\title{
APPLICATION OF SYNCHROTRON RADIATION X-RAY FLUORESCENCE TO INVESTIGATE THE DISTRIBUTION OF ARSENIC IN DIFFERENT ORGANS OF PANAX NOTOGINSENG
}

\author{
ChEn, L. ${ }^{1}-$ MI, Y. ${ }^{1 *}-$ WAN, X. ${ }^{2}-$ YIN, B. ${ }^{1}-$ YUAN, Z. ${ }^{3}-$ HE, L. ${ }^{1}-$ LI, Q. ${ }^{1}$ \\ ${ }^{1}$ Agri-Food Quality Standard and Testing Technology Institute, Yunnan Academy of \\ Agricultural Sciences, 9 Xueyun Road, Wuhua District, Kunming,Yunnan 650221, China \\ ${ }^{2}$ Institute of Geographic Sciences and Natural Resources Research, CAS, Beijing 100101, China \\ ${ }^{3}$ The Second Affiliated Hospital of Kunming Medical University, Kunming 650101, China \\ *Corresponding author \\ e-mail:yanhuami2015@163.com \\ (tel: +86-0871-65148394; mobile: 13759578727) \\ (Received 24 $4^{\text {th }}$ Oct 2016; accepted $20^{\text {th }}$ Dec 2016)
}

\begin{abstract}
This study investigated the micro area of cell tissue through synchrotron radiation X-ray fluorescence and high-performance liquid chromatography-atomic fluorescence spectrometry to indicate the effect of exogenous phosphorus (P) on the distribution of arsenic (As) absorption and the formation of As content in Panax notoginseng. Results showed that distributions of relative contents of As and $\mathrm{P}$ are the same in roots of $P$. notoginseng. Treatment with As $50 \mathrm{mg} / 1+\mathrm{P} 100 \mathrm{mg} / \mathrm{l}$ resulted in the decrease of As content in $P$. notoginseng. From stems and leaves of arsenic fluorescence distribution can be seen that arsenic into $P$. notoginseng plant and part of the trend of the transport to the ground, therefore rise to arsenic in the blade also is relatively small, mainly concentrated in the stem. Exogenous P treatment can effectively reduce the root's absorption and accumulation of As, thereby reducing the harmful effect of As on $P$. notoginseng.
\end{abstract}

Keywords: Panax notoginseng, arsenic, synchrotron radiation X-ray fluorescence, exogenous phosphorus, fluorescence spectrum

\section{Introduction}

Panax notoginseng is a perennial herb that has been used in traditional Chinese medicine for more than 600 years (Zhao, 2015). It can be used to disperse blood stasis and homeostasis and can play a role in detumescence and analgesic therapy (Yan et al., 2012). Wenshan Zhuang and Miao Autonomous Prefecture of China was origin country, in which $P$. notoginseng has planted more than 400 years, and accounts for $98 \%$ of the total production in China (Wang et al., 2004; Guo et al., 2010). However, arsenic (As) concentrations in the soils of this production area are elevated due to high background levels, frequent mining activities, and the large-scale use of As based pesticides and fertilizers (Ma, 2016).

Arsenic (As) is a poisonous and carcinogenic metal element. Human activities have allowed the entry of arsenic into water, soil, and plant systems; arsenic inevitably contaminated the food chain and medicinal materials and reached human bodies, thereby endangering health directly (Deng et al., 2005; Fitz andWenzel, 2002). While the soil-plant transfer of As is one of the principal pathways of human exposure to As (Tong et al., 2014). Some previous studies in Wenshan Zhuang and Miao Autonomous Prefecture demonstrated that As pollution contribution rate was $52.1 \%$, integrated pollution index was 0.67 , close to cordon ( $\mathrm{Li}, 2004)$, and As concentrations in $P$. 
notoginseng exceed the national standard $\left(<2 \mathrm{mg} \cdot \mathrm{kg}^{-1}\right)$ (Yan et al., 2012). Our study has found arsenate $(\mathrm{As}(\mathrm{V}))$ was almost exclusively identified in the soil, while be absorbed of arsenite (As (V)) can occur reduction and methylation in high proportions in P. notoginseng tissues (Ma et al., 2016). But we do not know clearly the distribution of arsenic in $P$. notoginseng tissue.

The aim of this study was to investigate the distribution arsenic of $P$. notoginseng's roots, stems, leaves at the micro scale. The As spatial distribution was determined using synchrotron X-ray fluorescence spectroscopy (SRXRF).

\section{Materials and methods}

\section{Plant cultivation}

We chose a testing area that has a good environment in which $P$. notoginseng plants had nearly similar plant height, stem diameter, and leaf area (stem diameter: $3-4 \mathrm{~mm}$; leaf width: $15-20 \mathrm{~mm}$; and root diameter: $7-8 \mathrm{~mm}$ ). The plants had been cultivated for one year and were adequately strong and healthy. In this study, seedlings were used for a solution culture test at different As densities. As was added as $\mathrm{Na}_{2} \mathrm{HAsO}_{4} \cdot 12 \mathrm{H}_{2} \mathrm{O}$. In the solution culture test, we used a complete nutrient solution that was adjusted according to the growth characteristic of $P$. notoginseng (Feng et al., 2003). All reagents of the solution were analytically pure format. Preculture treatments were performed $10 \mathrm{~d}$ before adding As. During preculture, the solution was changed once every 3d. Then, the test was performed for $3 \mathrm{~d}$, and sampling commenced. Three treatments were applied as following: (1) high As concentration treatment (As50mg/l); (2) high As concentration with addition of exogenous superphosphate $(\mathrm{P})(\mathrm{As} 50 \mathrm{mg} / \mathrm{l}+\mathrm{P} 100 \mathrm{mg} / \mathrm{l})$. Each treatment was repeated three times, after that the plants were left in the dark. The plant needs to be cultivated in a place with ventilation and transmittance of $8 \% \sim 12 \%$, temperature of $20^{\circ} \mathrm{C} \sim 25^{\circ} \mathrm{C}$, humidity of $30 \%$.

\section{$\mu-S R X R F$}

The middle part of the fresh root of $P$. notoginseng was chosen. An importembedding agent optimum cutting temperature compound was embedded in the middle part of the root. We used a freezing microtome LEICA CM1950 cryostat at $-20^{\circ} \mathrm{C}$ (Ager et al., 2002) with slice thickness of $10 \mu \mathrm{m}$. The frozen section adhesion on a polyethylene film sample frame was freeze-dried at $-80^{\circ} \mathrm{C}$ for the $\mu$-SRXRF scan. Micro-X-ray fluorescence ( $\mu$-SRXRF) microspectroscopy was performed at the 4W1B end station of Beijing Synchrotron Radiation Facility, which runs at $2.5 \mathrm{GeV}$ electron with $150 \sim 250 \mathrm{~mA}$ current. The incident X-ray energy was monochromatized by $4 \mathrm{WB} 1$ double multilayer monochromator at $15 \mathrm{keV}$ and was focused down to $50 \mu \mathrm{m}$ in diameter with polycapillary lens. 2D mapping was adopted by step mode. The sample was placed on a precision motor-driven stage, which scans $200 \mu \mathrm{m}$ stepwise. The $\mathrm{Si}(\mathrm{Li})$ solid state detector was used to detect X-ray fluorescence emission lines with a live time of $60 \mathrm{~s}$. Data reduction and processing were performed with PyMCA package (Solé et al., 2007). PyMCA fluorescence data processing software was used. OriginPro8.0 software was used to determine As distribution in the tap root. 


\section{Results}

\section{Distribution As in $P$. notoginseng roots}

In the test, we used $\mu$-SRXRF in a synchronic laboratory, as proposed by Institute of High Energy Physics Chinese Academy of Sciences. Then, the samples treated with high As concentration (As50mg/l), and high As concentration with exogenous $\mathrm{P}$ (As50mg/l+P100mg/l) were collected. The next step involved flake analysis. After data were subjected to a normalization process, spectrofluorimetry of the cross-section of three pairs of $P$. notoginseng samples was performed (Fig.1) illustrates that green and red represented fluorescence detection of low and high As concentrations, respectively. Meanwhile, synchrotron X-ray fluorescence spectroscopy spectrum of As distribution in roots. From top to bottom, As50mg/1 and As50mg/1+P100mg/1 were successively represented. Fig. $1 \mathrm{~A}$ is the spectrofluorimetry of the As in the root, whereas the right part points to the same testing part of the corresponding spectrofluorimetry of $\mathrm{P}$. The highest fluorescence level was equal to or lower than 15.63. Meanwhile, root samples treated with As50mg/l showed increased As fluorescence. The red part in the Figure 1 represents the area of high As concentration, in which fluorescence level was more than 8.49; fluorescence level in this area was obviously high. Most of the distributions of fluorescence levels in micro areas are at $7 \sim 10$. Samples treated with high As concentration adding exogenous $\mathrm{P}(\mathrm{As} 50 \mathrm{mg} / \mathrm{l}+\mathrm{P} 100 \mathrm{mg} / \mathrm{l})$ (Fig. $1 B$ )reached the peak fluorescence only at the level of 6.66, and this value was much lower than that obtained in samples treated with only As50mg/l. Samples treated with As50mg/l showed an uneven distribution of $\mathrm{P}$, according to spectrofluorimetry results. Some areas had high $\mathrm{P}$ levels, whereas other areas showed low P levels. Moreover, most of the areas with high As content had $\mathrm{P}$ spectrofluorimetry levels of more than 6 . Addition of exogenous $\mathrm{P}$ along with As treatment (As50mg/l+P100mg/l) nearly maintained a $\mathrm{P}$ spectrofluorimetry level of $5.7 \sim 8$. Combined vertical analyses on the distribution of fluorescent image from the roots treated with As and $\mathrm{P}$ showed that when roots were treated with As50mg/l, the As content increased. However, when roots were treated with As50mg/l+P100mg/l, As content decreased. Adding exogenous P would decrease As absorption into the roots. Using spectrofluorimetry results, the distribution patterns of As and $\mathrm{P}$ in the root were compared. Fig. 1 presents a horizontal comparison. The result indicates that increased As content would result in increased $\mathrm{P}$ content in the roots. This trend was obvious particularly when only high As concentration was supplied.

\section{Distribution As in P. notoginseng stems and leaves}

Different parts of $P$. notoginseng stems and leaves have different As contents (Fig. $1 C, D, E, F)$. As50mg/l test process of notoginseng arsenic stem appeared high fluorescence detection value, the highest is about 35.31, far higher than the root of the readings. Previous studies have found that there are a large number of stem in $P$. notoginseng arsenic reduction, methylation reaction such As much As (III) and MMA (Ma et al., 2016), it should be fluorescent values of the main causes of high stem. As50mg/l + P100mg/l values is low, only 5.88. Shows that added exogenous phosphorus removal can significantly reduce the arsenic content in the stem, and a drop of about 35.1\%. Blade As50mg/l and As50mg/l + P100mg/l treatment of arsenic fluorescence values are lower, show the arsenic content in $P$. notoginseng leaf is low. From stems and leaves of arsenic fluorescence distribution can be seen that arsenic into 
notoginseng plant and part of the trend of the transport to the ground, but as a result of arsenic is not nutrients, therefore rise to arsenic in the blade also is relatively small, mainly concentrated in the stem.
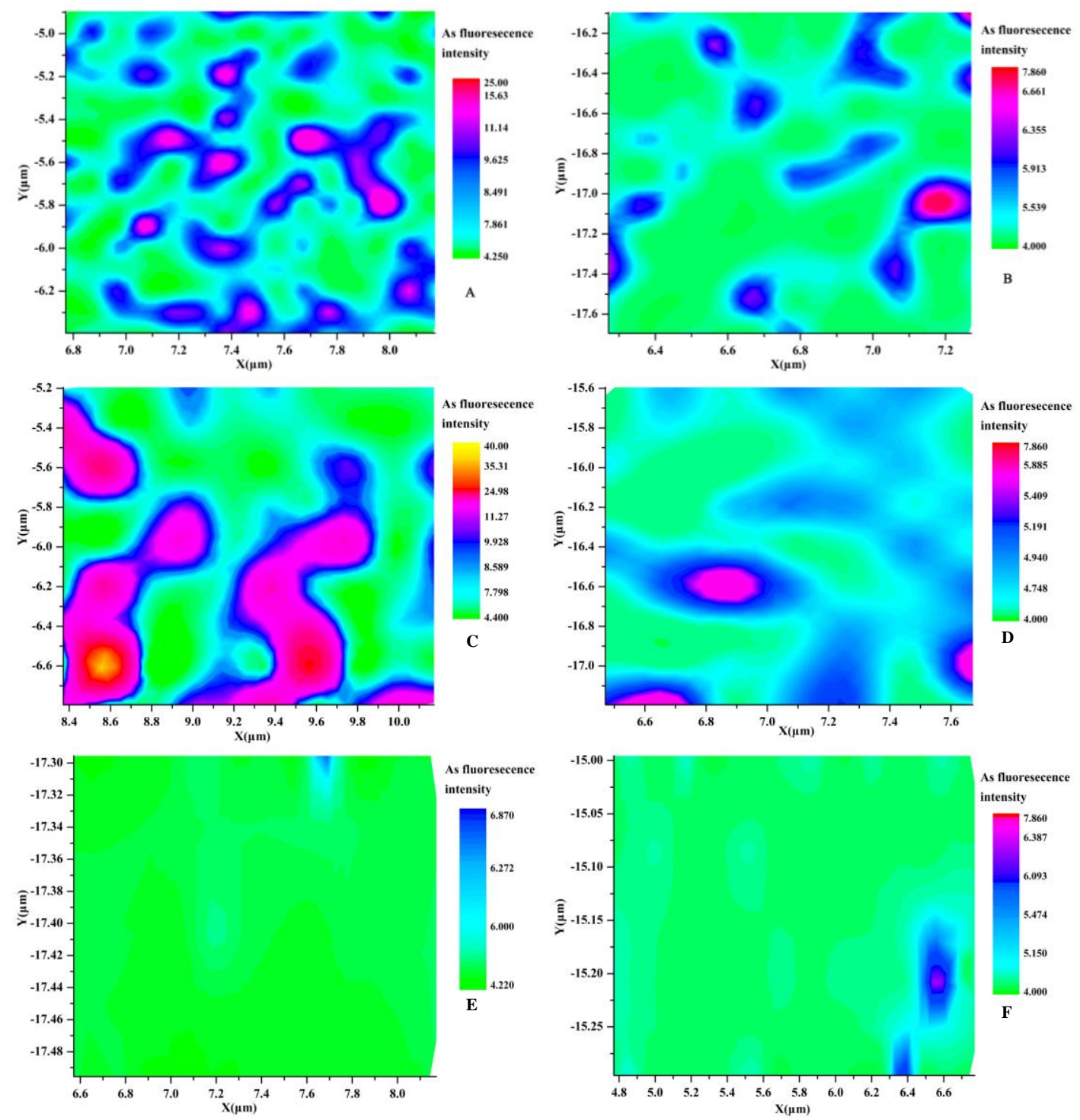

Figure 1. Synchrotron $X$-ray fluorescence spectrum of As distribution in roots of $P$. notoginseng (Note: A, C, E: As50mg/l; B, D, F: As50mg/l+P100mg/l; A, B: roots; C,D: stems; E, F: leaves)

\section{Discussion}

We have performed our study using exogenous $\mathrm{P}$ on characteristics of absorption of As in micro areas of Panax notoginseng and As distribution formation in unique Panax notoginseng production Yunnan province in southwest China. According to previous studies on plant-soil system, $\mathrm{P}$ inhibits absorption and accumulation of As (Koseki, 1988). Under high $\mathrm{P}$ conditions, $\mathrm{PO}_{4}{ }^{3-}$ and $\mathrm{AsO}_{4}{ }^{3-}$ compete for the membrane transporter. P and As show antagonism effects on each other (Sharples et al., 1998). The As resistance of rice (Meharg and MacNair, 1990), barley (Asher and Reay, 1979), alfalfa (Khattak et al., 1991), and Holcus lanatus L. (Meharg et al, 1994a,b; Meharg and 
MacNair, 1992) under high $\mathrm{P}$ conditions resulted in the reduction of As content in roots, stems, and seeds. When Pteris vittata was exposed to high As concentration, $\mathrm{P}$ and As were synergistic, i.e., adding $\mathrm{P}$ promoted the absorption and accumulation of As in the plant (Chen et al., 2002). This study investigated the characteristics of As distribution in the micro area of plants treated with high As concentration and high As concentration adding exogenous $\mathrm{P}$. The results of this study are consistant with previous studies which indicated that $\mathrm{P}$ and As absorption and accumulation occur in the same plant system (Meharg et al., 1994b; Buolo et al., 1999; Sharples et al., 2000). When exogenous P was added, $\mathrm{P}$ and As showed antagonistic effects. Exogenous $\mathrm{P}$ treatment inhibited the absorption and accumulation of As by $P$. notoginseng root.

Many studies have shown that the inhibitory effect on As(III) was significantly higher than that on As(V) (Carbonell-Barraehina et al., 1998; Sachs and Michael, 1971). This phenomenon occurred possibly because As and $\mathrm{P}$ have the same absorption point, i.e., the plant simultaneously absorbed As and P (Lei et al., 2003; Wang and Duan, 2009). As(III) is not affected by the damaging effects of $P$ oxide acidification, unlike As(V) (Marin et al., 1992). However, some researchers believe that the transformation of $\mathrm{As}(\mathrm{V})$ to $\mathrm{As}(\mathrm{III})$ in the plant is related to of the presence of reducing thiol glutathione in the plant (Tu et al., 2004). This material would transform As(V) into As(III) through desulfurization (Pickering et al., 2002; Delnomdedieu et al., 1993). In a previous study (Chen et al., 2014) on $P$. notoginseng, the author found that $\mathrm{As}(\mathrm{V})$ would be transformed into As(III) during the plant's absorption and transport of the element, thereby indicating the presence of reducing enzyme or thiol materials in $P$. notoginseng. The exact mechanism should be further investigated in our next study.

Acknowledgements. This study was sponsored by the National Natural Science Foundation of China (Grant No. 21267024), Science and Technology Projects for Youth of Yunnan Provincial (Grant No. 2014FD063), and Innovative Talent Training Project of Yunnan Province (Grant No. 2014HB059), and Team Training Project of Yunnan Province (2015HC025). We gratefully thank the staff at Beijing Synchrotron Radiation Facility (BSRF) for their generous help.

\section{REFERENCES}

[1] Ager, F.J., Ynsa, M.D., Dominguez, J.R., Gotor, C., Respaldiza, M.A. (2002): Cadmium localization and quantification in the plant Arabidopsis thaliana using Micro-PIXE. Nuclear Instruments and Methods in Physics Research B. 189:494-498.

[2] Asher, C.J., Reay, P.F.(1979): Arsenic uptake by barley seedlings. -Aust. J. Plant Physiol. 6(4):459-466.

[3] Buolo, F., Guijarro, I., Carbonell-Barrachina, A.A. (1999): Arsenic species: Effects on and accumulation by tomato plants. -J Agric Food Chem. 47(3):1247-1253.

[4] Carbonell-Barraehina, A.A., Aarabi, M.A., DeLaune, R.D. (1998): The influence of arsenic chemical form and concentration on Spartina patens and Spartina alterniflora growth and tissue arsenic concentration. -Plant and Soil 198(1):33-43.

[5] Chen, L., Mi, Y.H., Lin, X., Liu, D.H., Zeng, M., Chen, X.Y. (2014): Investigation and analysis of heavy metal pollution related to soil-Panax notoginseng system. -China J. of Chinese Materia Medica 39(14):2608-2613

[6] Chen, T.B., Fan, Z.L., Lei, M., Huang, Z.C., Wei, C.Y. (2002): Phosphorus on the centipede grass hyperaccumulation plants absorb the influence of arsenic and its scientific significance. -China Sci. Bul. 47(15):1156-1159. 
[7] Delnomdedieu, M., Basti, M.M., Otvos, J.D. (1993): Transfer of arsenic from glutathione to dithiols: a model of interaction. -Chemical Research in Toxicology 6:598-602.

[8] Deng, T.L., Liao, M.X., Jia, M.R. (2005): Heavy metals in Chinese herbal medicine GAP base soil and traditional Chinese medicine research. -Sichuan Science and Technology Press, Cheng Du, pp.7-8.

[9] Feng, G.Q., Jin, H., Chen, Z.J., Duan, C.Y., Cui, X.M., Kong, L.M.(2003): Studies of effects of different nutrients on the growth of Panax notoginseng. - Research and Practice of Chinese Medicines. S1:18-21.

[10] Fitz,W.J.,Wenzel,W.W.(2002): Arsenic transformations in the soil-rhizosphere-plant system: fundamentals and potential application to phytoremediation. -J. Biotechnol. 99:259-278.

[11] Guo, H.B., Cui, X.M., An, N., Cai, G.P.(2010): Sanchi ginseng (Panax notoginseng (Burkill) F.H. Chen) in China: distribution, cultivation and variations. Genet. Resour. Crop. -Evol. 57: 453-460.

[12] Khattak, R.A., Page, A.L., Parker, D.R.(1991): Accumulation and interactions of arsenic, selenium, molybdenum and phosphorus. -J. Environ Qual. 20(1):165-168.

[13] Koseki, K.(1988): Suppression of arsenic injury of rice plants by the application of higher phosphate concentration in culture solution. -Scientific Reports of the Miyagi Agricultural College (36):15-21.

[14] Lei, M., Chen, T.B., Fan, Z.L., Mo, L.Y., Huang, Z.C.(2003): Effect of phosphorus on arsenic adorption by three different soils. -Chinese Journal of Applied Eclogy 14(11):1989-1992.

[15] Li, W-D.(2004): Investigation on Environmental Quality of Panax notoginseng GAP Planting Areas in Wenshan District. -Yunnan Environmental Science 23(S):168-170.

[16] Ma, J., Han, Y.H., Zhou, X.Y., Wang, H.B., Lei, M., Li, Y.M.(2012): Effect of different extraction methods on arsenic speciation extraction in soil and pteris vittata L. -Modern Instruments 18(2):16-19.

[17] Ma, J., Mi, Y., Li, Q., Chen, L., Du, L., He, L., Lei, M. (2016): Reduction, methylation, and translocation of arsenic in Panax notoginseng grown under field. -Science of the Total Environment 550(15): 893-899

[18] Marin, A.R., Masscheleyn, P.H., Patrick, W.H.(1992): The influence of chemical form and concentration of arsenic on rice growth and tissue arsenic concentration. -Plant and Soil 139(2):175-183.

[19] Meharg, A.A., Bailey, J., Breadmore, K.(1994a): Biomass allocation, phosphorus nutrition and vesicular-arbuscular mycorrhizal infection in clones of Yorkshire Fog, Holus lanatus L. (Poaceae) that differ in their phosphate uptake kinetics and tolerance to arsenate. -Plant and Soil 160(1):11-20.

[20] Meharg, A.A., MacNair, M.R.(1990): An altered phosphate uptake system in arsenatetolerant Holcus lanatus L. -New Phytol. 116(1):29-35.

[21] Meharg, A.A., MacNair, M.R.(1992): Suppression of the high affinity phosphate uptake system: A mechanism of arsenate tolerance in Holcus lanatus L. -J. Exp. Bot.. 43(249):519-524.

[22] Meharg, A.A., Naylor, J., MacNair, M.R.(1994b): Phosphorus nutrition of arsenatetolerant and nontolerant phenotypes of velvetgrass. -J. Env. Qual. 23(2):234-238.

[23] Pickering, I.J., Prince, R.C., George, M.J.(2002): Reduction and coordination of arsenic in Indian mustard. -Plant Physiology. 122:171-178

[24] Sachs, R.M., Michael, J.L.(1971): Comparative phytotoxicity among four arsenical herbicides. -Weed Science. 19(5):558-564.

[25] Sharples, J.M., Meharg, A.A., Chambers, S.M.(1998): Arsenic sensitivity in ericoid and ectomycorrhizal fungi. -Environ Toxic Chem. 18(8):1848-1855.

[26] Sharples, J.M., Meharg, A.A., Chambers, S.M.(2000): Evolution: Symbiotic solution to arsenic contamination. -Nature. 404:951-952. 
[27] Solé, V.A., Papillon, E., Cotte, M., Walter P., Susini, J.(2007): A multiplatform code for the analysis of energy-dispersive X-ray fluorescence spectra. -Spectrochim Acta B. 62(1):63-68.

[28] Tong, J.T., Guo, H.M., Wei, C.(2014): Arsenic contamination of the soil-wheat system irrigated with high arsenic groundwater in the Hetao Basin, Inner Mongolia, China. -Sci. Total Environ. 496: 479-487.

[29] Tu, S., Ma, L.Q., MacDonald, G.E.(2004): Effects of arsenic species and phosphorus on arsenic absorption, arsenate reduction and thiol formation in excised parts of Pteris vittata L. -Environmental and Experimental Botany. 51(2):121-131.

[30] Wang, C.L., Chen, Z. J., Cui, X. M.,Sun, Y. Q.(2004): The characteristics of products of designations of origin of Panax notoginseng in Wenshan. -China Journal of Chinese Materia Medica 29(6):511-514

[31] Wang, L.H., Duan, G.L.(2009): Effect of external and internal phosphate status on arsenic toxicity and accumulation in rice seedlings. -J. Environ. Sci.-China 21(3):346-351.

[32] Yan, X.L., Lin, L.Y., Liao, X.Y., Zhang, W.B.(2012): Arsenic accumulation and resistance mechanism in Panax notoginseng, a traditional rare medicinal herb.Chemosphere 87: 31-36.

[33] Zhao, Y.Q.(2015): Panax notoginseng (Burk.) - In: Chen, F.H. (Ed.) Sanqi, Notoginseng. Dietary Chinese Herbs. Springer Vienna. pp. 185-193. 